tap. This will prevent the harmless " snap" from the mixture in the small chamber at the joining of the gas tubes. If a disc more than eight feet be required for the microscope, it will be well to use hydrogen gas instead of ether, since the calibre of the jet cannot in the ether light very well exceed $\frac{1}{1+}$ of an inch.

As an extra security, I pack the mixing chamber with asbestosfibre, moistened with glycerine; but, as before urged, the oxygen must leave the saturator, saturated.

To insure the coincidence of the foci of the reflector with the optical axis of the microscope, it will be well to place three adjusting screws in a triangle behind the mirror, and this last may have both a smali vertical and horizontal movement.

I claim for this catoptric arrangement a larger grasp of light than can be got from ordinary lenses, and this may be effected al:o ar a small oullay. For the amateur constructor the plan wiil afford many advantages.

G. B. Buckton.

Note on the Colours of the Alkali Metals.

WHEN these metals are heated in a vacuous tube in such a way as to cause an txtremely thin sublimate of the metal to condense upon the glass, the film so obtained will be found to possess a beautiful and strongly-marked colour. That this colour is not in any way due to the combination of the metal with any lingering minute traces of oxygen, is evident from the fact that vacuous tubes which have contained the clean and bright metal for years, and in which the metal has been frequently melted and rolled about, and even vapourized in places, and in which, therefore, it is impossible to conceive of any oxygen remaining, will continue to show the phenomenon whenever a portion of the contained metal is heated. The experiment may readily be made by introducing a freshly-cut fragment of the metal into a glass tube sealed at one end and drawn down to a narrow and thickened constriction near the middle. The tube is then drawn out at the open end and connected to a Sprengel pump. As soon as a good vacuum is obtained the tube is warmed through. out its entire length, the pump being still in operation, and the metal heated sufficiently high to cause it to melt and run out of the crust of oxide. When the exhaustion is again as complete as possible the tube is sealed off. The metal is once more melted, the whole tube being at the same time gently heated, and the molten mass allowed to filter through the constriction into the other portion of the tube. The vacuous condition of the tube allows of the metal freely running through an extremely fine aperture, and in this way it becomes perfectly separated from all dross. The tube is then sealed off at the constriction. On gently heating a minute fragment of the bright metal so obtained, by means of a small pointed gas flame, the coloured film of sublimed metal will at once be seen. Viewed by transmitted light, the colour of the film of sodium thus obtained is greenishblue, inclining to green. Potassium gives a sublimate which is of a magnificent rich purple colour, while rubidium, on the other hand, forms a film which is a pure indigo blue.

In the cases of sodium and potassium, the colour of the metallic sublimates is different from the colour of the vapour as seen when the metals are boiled in an atmosphere of hydrogen. Potassium, it will be remembered, yields under these circumstances a vapour possessing an emerald-green colour, while that of sodium, which appears colourless when seen in small layers, shows a violet or purple colour when viewed through a sufficient thickness.

When the liquid alloy of sodium and potassium is treated in the same way, the sublimate obtained is found to be greenish in colour nearest to the source of heat, quickly shading off to blue and purple as it is more remote from that point, indicating apparently that the two metals sublime separately.

As a means of observing these colour phenomena, this alloy is more advantageously employed than the solid metals themselves, for, by rolling the liquid about, the sublimate may be wiped away and the experiment repeated indefinitely in the same tube.

As to whether the colours of these sublimed films are properties intrinsic to the particular metals, or are merely a function of the physical condition of the substances, it is perhaps rash to dogmatize. A number of other elements have been treated in a similar manner, but without similar results; thus lithium, cadmium, mercury, arsenic, tellurium, and selenium, when heated in vacuous tubes are readily sublimed, but in no case does the film appear coloured. On the other hand, however, it is well known that some of the very malleable metals when beaten out into thin films are capable of transmitting light varying in colour from $g$ een to violet.

G. S. NEWTH.
Women and Musical Instruments.

IN answer to Prof. O. T. Mason's letter which appeared in a recent number of NATURE (vol. xlvi. p. 56I), I may draw attention to the following facts which bear upon a part of the subject which he broaches, namely, the part played by savage women in the use of musical instruments. In the South Pacific the "noseflute" is very generally, though by no means exclusively, played upon by women. In the account of the voyage of Capts. Cook and King there is in one of the plates a figure of a woman of the "Tonga Islands seated under a hut playing upon a "noseflute." A similar figure of a woman playing upon a "nose-flute" may be seen in plate 28 of Labilladière's "Voyage de la Perouse," in the representation of a Tongan double-canoe. Melville ("Four Months' Residence in the Marquisas Islands," p. 25I) mentions playing upon the "nose-flute" as being "a favourite recreation with the females." In Wilkes' "U. S. Exploring Expedition," iii. p. 190, there is a description of this instrument as used in the Fiji Islands, and it is stated that " no other instrument but the flute ['nose-flute'] is played by the women as an accompaniment to the voice."

Turning now to another genus of primitive instıuments, viz., the "musical bow," we find a peculiar local form, the "Pangolo," occurring at Blanche Bay, New Britain. There are specimens of this at Berlin and Vienna. This instrument is stated by Dr. O. Finsch (Ann. des $K$. K. Naturhist. Hofmuseums, suppl. vol. iii. pt. I, p. III) to be only played upon by women of Blanche Bay. Guppy too " Solomon Islands," p. I42), says that the women of Treasury Island produce a soft kind of music by playing, somewhat after the fashion of a jew's-harp, on a lightly-made fine-stringed bow about 15 inches long.

It cannot, I believe, be said that any of these instruments have been invented by women, and it is undoubted that women in savagery but seldom figure as performers upcn musical instruments. It would certainly be interesting to collect all the instances recorded. I hope that the above few notes regarding instruments in the south Pacific may be of use to Prof. Mason, and I can only regret that lack of the necessary time prevents my going further into the matter.

University Museum, Oxford, HENRy Balfour. November 7 .

\section{AN ANCIENT GLACIAL EPOCH IN AUSTRALIA.}

A. VERY interesting "special report" has just been issued by the Department of Mines of Victoria, giving an account of the remarkable evidences of glaciation observed at a locality about twenty miles southeast of Sandhurst, and about the same distance north of the great Dividing Range. ${ }^{1}$ The report is illustrated by a map and sections on a large scale, and by eight excellent photographic prints, showing the character of the deposit on the surface and in railway cuttings, the striated bed rock, and the striated and grooved blocks and boulders, so that full materials are given for the conclusion that we have here an undoubted glacial deposit. A brief summary of this report will therefore be interesting to all students of the phenomena and problems of terrestrial glaciation.

The district now specially described is about fifteen miles in one direction by five in another, and over this area of about thirty-six square miles the conglomerate is continuous, overlying the Silurian rocks of the district. It has generally a rounded or undulating surface, but shows cliffs about Ioo feet high in some of the gullies, and its maximum thickness is estimated at 300 or 400 feet, while its highest point is about 700 feet above sea-level. As well seen in the cliffs and several railway cuttings, the conglomerate consists of a matrix of sand and clayey matter containing huge boulders, great angular and subangular masses of rock, pebbles, and rock-fragments of endless variety of size, form, and material. Many of these masses are planed, scored, striated, or polished.

I "Notes on the Glacial Conglomerate, Wild Duck Creek." By E. J. Dunn, F.G.S. (R. S. Brain, Government Psinter, Melbourne, 1892.)

No. I 203 , VOL. 47] 